\title{
Effect of enhanced psychosocial care on antipsychotic use in nursing home residents with severe dementia: cluster randomised trial
}

\author{
Jane Fossey, Clive Ballard, Edmund Juszczak, Ian James, Nicola Alder, Robin Jacoby, Robert Howard
}

\begin{abstract}
Objective To evaluate the effectiveness of a training and support intervention for nursing home staff in reducing the proportion of residents with dementia who are prescribed neuroleptics.

Design Cluster randomised controlled trial with blinded assessment of outcome.

Setting 12 specialist nursing homes for people with dementia in London, Newcastle, and Oxford.

Participants Residents of the 12 nursing homes; numbers varied during the study period.

Intervention Training and support intervention delivered to nursing home staff over 10 months, focusing on alternatives to drugs for the management of agitated behaviour in dementia. Main outcome measures Proportion of residents in each home who were prescribed neuroleptics and mean levels of agitated and disruptive behaviour (Cohen-Mansfield agitation inventory) in each home at 12 months.

Results At 12 months the proportion of residents taking neuroleptics in the intervention homes $(23.0 \%)$ was significantly lower than that in the control homes (42.1\%): average reduction in neuroleptic use $19.1 \%$ (95\% confidence interval $0.5 \%$ to $37.7 \%)$. No significant differences were found in the levels of agitated or disruptive behaviour between intervention and control homes.

Conclusions Promotion of person centred care and good practice in the management of patients with dementia with behavioural symptoms provides an effective alternative to neuroleptics.
\end{abstract}

\section{Introduction}

A large proportion of nursing home residents with dementia receive major tranquillisers for behavioural symptoms, ${ }^{12}$ despite evidence of only modest efficacy, high placebo response, ${ }^{34}$ and serious adverse events. ${ }^{5}$ Good practice guidelines recommend that psychological or environmental management options should be the first line approach and that drugs should be stopped after symptoms have been absent or minimal for three months. ${ }^{6}$ Individually tailored interventions based on antecedent behaviour consequence assessments ${ }^{7}$ and the "tool box" approach $^{8}$ are effective at the patient level. Liaison and staff training interventions have short term benefits, ${ }^{90}$ although a review of 48 studies showed limited evidence for the sustained implementation of knowledge. ${ }^{11}$

We carried out a cluster randomised controlled trial to determine whether behavioural symptoms in people with severe dementia could be safely managed with an intervention package (focused intervention training and support) to reduce the proportion being treated with neuroleptics.

\section{Methods}

We used a cluster trial design primarily to avoid contamination (because care staff receiving extra training and support could not be expected to treat individual residents differently) but also for practical purposes. The intervention was aimed at changing clinical practice in the nursing home, and hence the home was the unit of randomisation and analysis.

\section{Sample size}

We estimated that about $55 \%$ of residents would be taking neuroleptics at the start of the trial and that we could reduce this to $30 \%$ in the intervention arm by 12 months. For a conventional trial with randomisation of individual patients to be able to detect such a reduction, a minimum of 69 patients would need to be recruited to each arm of the trial (138 patients in total), for a significance level of $5 \%$ (two sided), a power of $85 \%$, and equal allocation. As we used cluster randomisation for the purposes of our study, the implications of this are reduced efficiency and loss of power. $^{12}$ We therefore required a larger sample size to compensate for this design effect (the ratio of the total number of patients required using cluster randomisation to the number required using individual randomisation). The formula $1+[(\mathrm{m}-1) \times \mathrm{r} 1]$ where $\mathrm{r} 1=\mathrm{s}^{2} \mathrm{~b} /\left(\mathrm{s}^{2} \mathrm{~b}+\mathrm{s}^{2} \mathrm{w}\right)$, the intracluster correlation coefficient, is used where $s^{2} b$ is the variance between clusters and $\mathrm{s}^{2} \mathrm{w}$ is the variance within clusters. Based on the additional assumptions of an estimated intracluster correlation coefficient of 0.05 and an average of 30 eligible and consenting patients in each cluster: $1+(30-1) \times 0.05=2.45$ we would need $2.45 \times 69=170$ eligible patients per arm, which is in the order of six clusters (nursing homes) per arm, or 12 clusters in total.

\section{Participants and randomisation}

We recruited residents within 12 nursing homes, four each in London, Newcastle, and Oxford. Eligible homes were those registered to accept elderly mentally impaired people and with a minimum of $25 \%$ of residents with dementia who were taking neuroleptic drugs.

The trial's manager enrolled the nursing homes. Consent was obtained from the management of the homes, and the family carers of residents were asked to give consent for involvement of their relatives. Research assistants carried out baseline assessments before randomisation. As neuroleptic prescribing levels varied between the groups, the trial's statistician (blind to the identity of the homes) classified two homes in each region as having low neuroleptic use and two as having high use. The stat- 
istician then randomly assigned the homes to intervention or control, stratified by region and baseline neuroleptic use. The allocations were computer generated using stratified block randomisation (fixed block size of two) with Stata version 8.

\section{Procedure}

A consultant old age psychiatrist $(\mathrm{RH}, \mathrm{CB}$, and $\mathrm{RJ})$ and a senior member of nursing staff from each home reviewed the drug prescriptions of the residents after completion of the baseline assessments but before randomisation. This review followed good practice guidelines ${ }^{6}$ and included recommending stopping psychotropic drugs that had been prescribed for more than three months and discontinuing the drug when behavioural problems had resolved. The psychiatrists wrote to the prescribing doctors for each home (usually general practitioners) to communicate the recommendation and telephoned if no action had been taken after two weeks. Reviews took place every three months. The psychiatrists were robust in their efforts to reduce psychotropic prescribing. Homes randomised to the intervention arm agreed to the trial's clinician working with them for two days a week for 10 months. Homes randomised to the control arm received treatment as usual. No restrictions were placed on training and supervision activities in any of the homes.

\section{Intervention}

The package was delivered by a psychologist, occupational therapist, or nurse based in each of the three centres. These staff received training in the delivery of person centred care and skills development in training and supervision. They were supervised weekly over the study period by JF and IJ, both experienced in dementia care. The package involved a systemic consultation approach. $^{13}$ This tackled "whole home" issues, such as environmental, care practice, and attitudinal factors. The clinicians started and supported the use of activities through didactic training, skills modelling, and supervision of groups and individual staff. Key elements in the programme involved initial skills training, behavioural management techniques, and ongoing training and support. Initial skills training for care staff involved the philosophy and application of person centred care, ${ }^{14}$ positive care planning, ${ }^{15}$ awareness of environmental design issues, the use of antecedent behaviour consequence models,$^{16}$ development of individualised interventions, active listening and communication skills, reminiscence techniques, ${ }^{17}$ and involvement of family carers. Behavioural management techniques included training in the Cohen-Mansfield approach. ${ }^{8}$ Ongoing training and support included group supervision and further development of skills involving individual case supervi$\operatorname{sion}^{18}$ and supervision of issues requiring organisational change within the home. ${ }^{19}$

\section{Assessments and measures}

Each patient's daily dose of drugs was translated into chlorpromazine daily equivalents according to the British National Formulary. The Cohen-Mansfield agitation inventory ${ }^{20}$ was used to measure the reported agitated and disruptive behaviours of residents. Dementia care mapping, an observational tool for quality of life research, was used to develop person centred care practice. ${ }^{21}$ Baseline assessments were carried out by the trial's clinicians and psychology research assistants. Assessments at 12 months were carried out by a psychology research assistant who had not been employed during the intervention period. This member of staff was blind to the homes' intervention: the trial's staff did not identify the intervention homes to the researcher and nursing home staff were asked not to discuss their homes' intervention with the researcher. Despite these efforts, because the package was designed to influence the whole care approach of staff, it is likely that the research assistant would have been able to detect which homes had received the intervention.

\section{Data analysis}

Primary outcomes (at the cluster level) were the proportion of patients receiving neuroleptic treatment at 12 months and the mean dose of neuroleptic. Secondary outcomes were agitation, patient level quality of life, proportion of patients taking other psychotropic drugs, adverse events (including documented falls), and incidents involving irritable behaviour directed at staff or other residents.

Analysis followed a prespecified plan based on an intention to treat basis; all clusters with available data were analysed in the groups to which they were allocated. With only six clusters in each group, it was not possible for us to carry out analyses at individual level, since the large sample approximations underlying these procedures are questionable. ${ }^{22}$ All primary analyses were therefore carried out at the cluster level using a weighted two sample $t$ test, weighted by the number of patients in each home. Although the test assumes no severe departures from normality, it is remarkably robust to violations of the underlying assumptions, especially when there are equal numbers of clusters assigned to each intervention group. ${ }^{22}$ The assumptions of the test are also more likely to be satisfied if a weighted analysis is carried out. With only six clusters in each group, the Shapiro-Wilk test for normality will have low power, and a histogram may be difficult to interpret. We therefore used the non-parametric Wilcoxon signed rank test as a sensitivity analysis to test for differences between the groups. In principle, a stratified design should be accompanied by a stratified analysis, but with such a small number of clusters and two stratification variables it is unlikely that the gain in precision would outweigh the loss in degrees of freedom. ${ }^{23}$ For primary outcomes we used a weighted linear regression analysis (weighted by cluster size) as a sensitivity analysis, to adjust for the stratification factors. For the primary outcome, the proportion of patients receiving neuroleptics at 12 months, we present results for each cluster (nursing home) graphically in a bubble plot, where the size of the bubble is proportional to the size of the cluster, and for each intervention group, equivalent to the weighted mean of the cluster specific proportions for each randomised group. We express the treatment effect as the difference between the two weighted means, along with a 95\% confidence interval, $\mathrm{P}$ value, and intracluster correlation coefficient. Subsequent analyses for the coprimary and secondary outcomes were based on the 12 cluster specific proportions for dichotomous outcomes, and the means or medians, depending on normality, for continuous outcomes. We used the weighted $t$ test to compare the appropriate summary measures obtained for each cluster. Treatment effect sizes are expressed as the difference between the treatment groups, along with 95\% confidence intervals, $\mathrm{P}$ values, and intracluster correlation coefficients. All analyses were carried out using Stata version 8.

\section{Results}

Six care homes were randomised to the training and support intervention and six to treatment as usual (control homes; fig 1). All residents, not just those present, were analysed at each time point. This did not affect the primary analyses, carried out on the follow-up data at 12 months only.

Personal and clinical characteristics of the residents in both arms were similar at baseline (table 1). 
Table 1 Baseline personal and clinical characteristics of residents of care homes assigned to focused training and support package or usual care (control). Values are numbers (percentages) of residents unless stated otherwise

\begin{tabular}{|c|c|c|}
\hline Characteristics & $\begin{array}{l}\text { Control homes }(n=6 \\
168 \text { residents) }\end{array}$ & $\begin{array}{l}\text { Intervention homes } \\
\text { ( } \mathrm{n}=6 ; 181 \text { residents) }\end{array}$ \\
\hline Median (range) age (years) & $82(53-101)$ & $82(60-98)$ \\
\hline Men & $102 / 168$ (61) & $117 / 181$ (65) \\
\hline Taking neuroleptics & $83 / 167(50)$ & $85 / 181 \quad(47)$ \\
\hline $\begin{array}{l}\text { Median (range) dose of neuroleptic in } \\
\text { chlorpromazine equivalents (No of } \\
\text { patients) }\end{array}$ & $100(12.5-630)(n=83)$ & $100(10-1200)(n=84)$ \\
\hline Taking other psychotropics & $89 / 168$ (53) & $98 / 181 \quad(54)$ \\
\hline A least one fall in past 12 months & $98 / 168 \quad(58)$ & $101 / 169(60)$ \\
\hline $\begin{array}{l}\text { Median (range) Cohen-Mansfield } \\
\text { agitation inventory* }\end{array}$ & $37(29-118) n=163$ & $39(29-114) n=167$ \\
\hline $\begin{array}{l}\text { At least one episode of aggression in } \\
\text { past } 12 \text { months }\end{array}$ & 26/168 (15.5) & $11 / 169(6.5)$ \\
\hline \multicolumn{3}{|l|}{ Clinical dementia rating: } \\
\hline None, questionable, or mild & $37 / 163(23)$ & $25 / 170(15)$ \\
\hline Moderate & $32 / 163(20)$ & 46/170 (27) \\
\hline Severe & $94 / 163(58)$ & $99 / 170(58)$ \\
\hline $\begin{array}{l}\text { Median (range) wellbeingtł (No of } \\
\text { patients) }\end{array}$ & $\begin{array}{c}0.9 \begin{array}{l}(-2.5 \text { to } 2.6) \\
(n=145)\end{array}\end{array}$ & $\begin{array}{c}0.8 \begin{array}{l}(-1.7 \text { to } 2.5) \\
(n=160)\end{array}\end{array}$ \\
\hline Spending some $(>0 \%)$ time asleep $\neq$ & 111/145 (77) & 124/160 (78) \\
\hline $\begin{array}{l}\text { Spending some }(>0 \%) \text { time } \\
\text { withdrawn } \neq\end{array}$ & $98 / 145(68)$ & 103/160 (64) \\
\hline
\end{tabular}

*Range 29-203; higher scores mean more agitation (scores >40 usually accepted as clinically significant)

†Range -5 to 5

tEstimated using dementia care mapping.

\section{Neuroleptic use}

At 12 months' follow-up, 40 of 174 (23.0\%) residents in the intervention homes were taking neuroleptics compared with 69 of $164(42.1 \%)$ in the control homes: average reduction 19.1\% (95\% confidence interval $0.5 \%$ to $37.7 \%$ ). With one exception, little or no overlap was found in the proportion of residents using neuroleptics in each home across the treatment groups (figs 2 and 3). To examine the robustness of this result, a sensitivity analysis

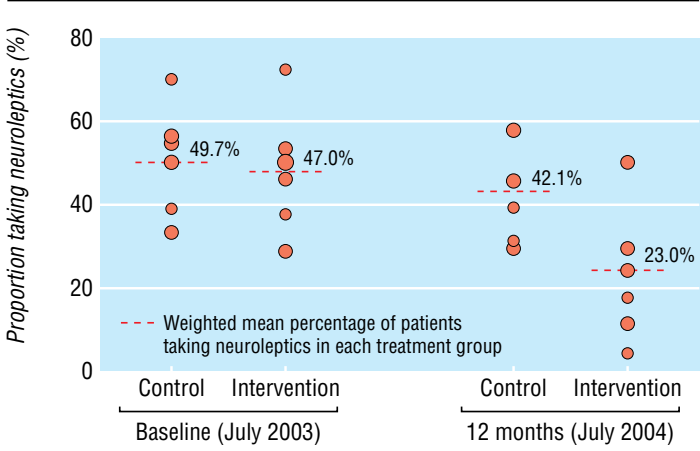

Fig 2 Neuroleptic use at baseline and 12 months in homes allocated to training and support intervention or to treatment as usual (size of circle proportional to size of cluster). As control homes have almost identical proportions of residents taking neuroleptics at 12 months, points overlap and appear to be only five

was carried out excluding residents with conditions that precluded the withdrawal of neuroleptics (for example, residents with a primary diagnosis of schizophrenia, bipolar disorder, or psychotic depression who are increasingly placed in nursing homes registered for dementia care). After exclusion of these residents from analysis, 28 of $161(17.4 \%)$ residents in the intervention group were taking neuroleptics at 12 months compared with 60 of $155(38.7 \%)$ in the control group: average reduction $21.3 \%$ ( $4.3 \%$ to $38.3 \% ; \mathrm{P}=0.02)$. A further sensitivity analysis, adjusting for stratification variables (baseline neuroleptic use and region), gave an average reduction in neuroleptic use of $19.4 \%$ $(-3.0 \%$ to $41.7 \% ; \mathrm{P}=0.08)$

\section{Dose of neuroleptic}

Data on dose of neuroleptics did not follow the normal distribution. The median was therefore the appropriate summary statistic for each cluster, and the mean of the medians between groups was compared. At 12 months the mean dose was 107.1 in the control group and 102.1 in the intervention group: average difference 4.9 ( -20.0 to $29.9 ; \mathrm{P}=0.67$ : table 2 ). Adjusting for strati-

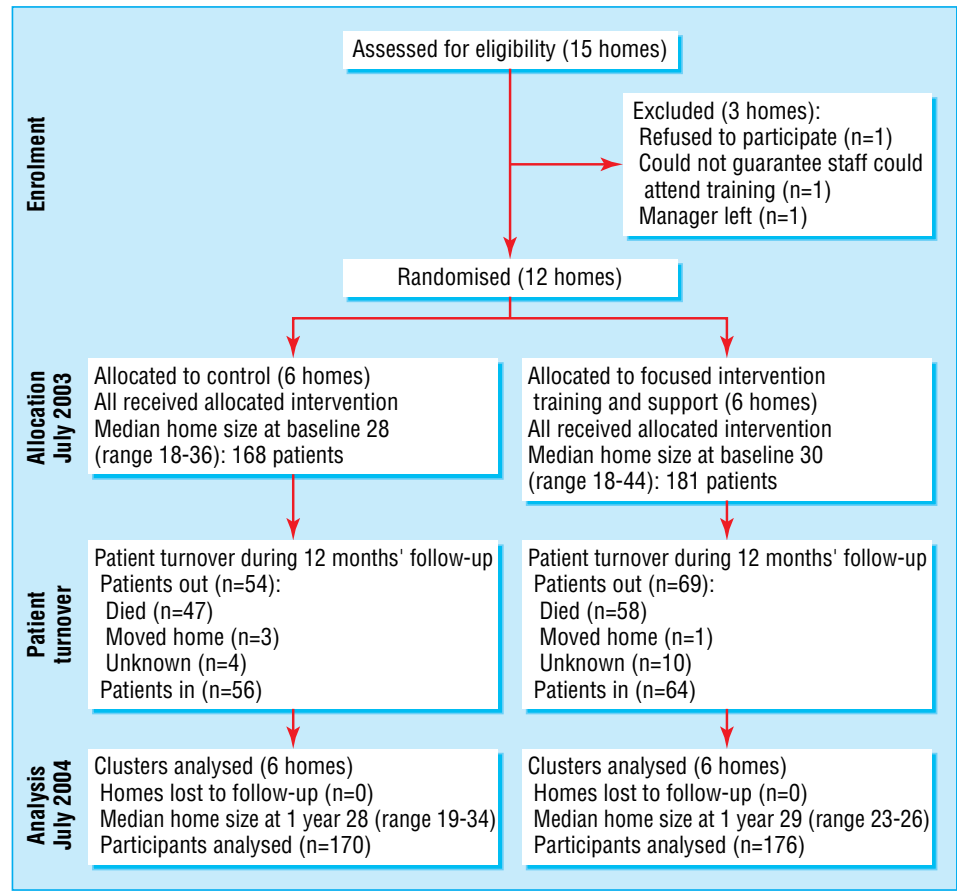

Fig 1 Flow of nursing homes and residents through trial 


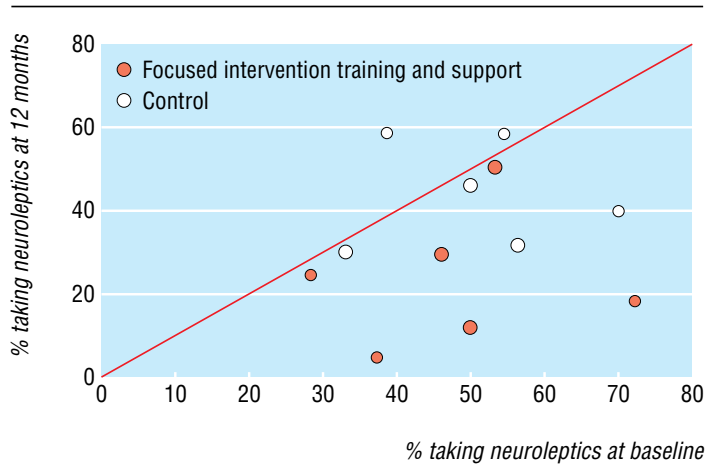

Fig 3 Percentage of residents prescribed neuroleptics in each home (size of circle proportional to size of home). Diagonal line represents no change in percentage of residents taking neuroleptics from baseline to 12 months. Homes above line experienced increase in percentage of residents taking neuroleptics and homes below line experienced decrease. Homes near line show little change

fication variables confirmed this result (average difference 4.0, -22.0 to 29.9; $\mathrm{P}=0.73$ ). After excluding those residents for whom withdrawal of neuroleptics would have been contraindicated, this difference increased to $19.3(-7.0$ to $45.7 ; \mathrm{P}=0.13)$, with a mean dose of 114.3 in the control group and 94.9 in the intervention group.

\section{Other psychotropic drugs and falls}

At 12 months the average proportion of residents taking other psychotropics was 109 of $174(62.6 \%)$ in the intervention group and 92 of $162(56.8 \%)$ in the control group: a non-significant difference $(5.9 \%,-27.2 \%$ to $15.5 \% ; \mathrm{P}=0.56)$ suggesting that neuroleptics were not simply replaced with other psychotropic drugs. Similar proportions of residents had at least one fall in the past 12 months-91 of $175(52.0 \%)$ in the intervention group and 90 of $165(54.6 \%)$ in the control group: average difference $2.6 \%,-18.7 \%$ to $23.8 \%$.

\section{Agitation and aggression}

No significant differences were found between the intervention and control groups in levels of agitation at 12 months (mean difference $0.3,-8.3$ to $8.9 ; \mathrm{P}=0.94$ ).

At least one episode of aggression was recorded for 14 of 173 $(8.1 \%)$ residents in the intervention group compared with 16 of
$165(9.7 \%)$ in the control group: average difference $1.6 \%$ $(-12.7 \%$ to $15.8 \% ; \mathrm{P}=0.25)$.

\section{Quality of life and wellbeing}

Ratings for wellbeing in residents in the intervention group were similar to those in the control group ( $1.1 v 0.9$, mean difference $-0.2,-0.5$ to $0.2 ; \mathrm{P}=0.29)$. A marginal advantage was shown for the intervention group in the proportion of residents spending at least some time withdrawn during the six hour observation period $(37.6 \% \vee 46.4 \%$, average difference $8.8 \%,-25.2 \%$ to $42.8 \% ; \mathrm{P}=0.58$ ). The proportion of residents who spent at least some time asleep was similar between the groups: 110 of 149 $(73.8 \%)$ for the intervention arm $v 114$ of $153(74.5 \%)$ for the control arm.

\section{Discussion}

An intervention offering support with individualised psychological intervention as part of a programme promoting person centred care and good practice provides a viable alternative to neuroleptics for treating behavioural symptoms in patients with dementia.

In both intervention and control homes in our study, psychiatrists reviewed the prescriptions of the residents and recommended withdrawal of neuroleptics in accordance with best clinical practice, yet significantly fewer residents in the intervention homes remained taking these drugs. The percentage of residents (after excluding those with schizophrenia or other psychotic disorders) who were still prescribed neuroleptics at the end of 12 months was less than half that in the control homes. Levels of agitation and episodes of aggressive behaviour did not increase in homes with reduced prescribing of neuroleptics.

Cohen-Mansfield et al carried out a placebo controlled cross over trial of neuroleptic withdrawal in patients with dementia and found no significant worsening of behavioural symptoms when drugs were replaced with a tailored psychological intervention. ${ }^{8}$ In another study, ${ }^{9} 89$ people with dementia from a large community nursing home were randomised to receive either a complex intervention including activities, guidelines for drug use, and educational rounds, or treatment as usual. Patients who received the active intervention showed a significant

Table 2 Main outcomes at 12 months. Values are numbers (percentages) of nursing home residents unless stated otherwise

\begin{tabular}{|c|c|c|c|c|c|}
\hline Outcome & $\begin{array}{c}\text { Control homes }(\mathrm{n}=6 ; 170 \\
\text { residents) }\end{array}$ & $\begin{array}{l}\text { Intervention homes ( } \mathrm{n}=6 ; 176 \\
\text { residents) }\end{array}$ & $\begin{array}{l}\text { Weighted mean difference }(95 \% \\
\qquad \mathrm{Cl})^{\star}\end{array}$ & P value ${ }^{\star}$ & $\begin{array}{c}\text { Intracluster correlation } \\
\text { coefficient }\end{array}$ \\
\hline Taking neuroleptics & 69/164 (42) & $40 / 174(23)$ & 19.1 (0.5 to 37.7$)$ & 0.045 & 0.10 \\
\hline $\begin{array}{l}\text { Meant (SD) median dose in } \\
\text { chlorpromazine equivalents (No of } \\
\text { patients) }\end{array}$ & $\begin{array}{c}107.1(15.4) \\
(n=69)\end{array}$ & $\begin{array}{c}102.1(23.1) \\
(n=40)\end{array}$ & $4.9(-20.0$ to 29.9$)$ & 0.67 & $0 \neq$ \\
\hline Taking other psychotropics & $92 / 162(57)$ & 109/174 (63) & $-5.9(-27.2$ to 5.5$)$ & 0.56 & 0.080 \\
\hline At least one fall in past 12 months & $90 / 165(55)$ & $91 / 175(52)$ & $2.6(-18.7$ to 23.8$)$ & 0.27 & 0.061 \\
\hline $\begin{array}{l}\text { Mean† (SD) Cohen-Mansfield agitation } \\
\text { inventory§ total (No of patients) }\end{array}$ & $\begin{array}{c}42.0(5.9) \\
(n=162)\end{array}$ & $\begin{array}{c}41.6(7.2) \\
(n=172)\end{array}$ & $0.3(-8.3$ to 8.9$)$ & 0.94 & 0.087 \\
\hline $\begin{array}{l}\text { At least one episode of aggression in } \\
\text { past } 12 \text { months }\end{array}$ & $16 / 165(10)$ & $14 / 173(8)$ & $1.6(-12.7$ to 15.8$)$ & 0.25 & 0.10 \\
\hline $\begin{array}{l}\text { Meant (SD) wellbeing } \|^{\star *} \text { (No of } \\
\text { patients) }\end{array}$ & $\begin{array}{c}0.9(0.35) \\
(n=153)\end{array}$ & $\begin{array}{c}1.1(0.04) \\
(\mathrm{n}=149)\end{array}$ & $-0.2(-0.5$ to 0.2$)$ & 0.29 & 0.075 \\
\hline Spending some time $(>0 \%)$ asleep ${ }^{* *}$ & $114 / 153(75)$ & $110 / 149(74)$ & $0.7(-8.5$ to 9.9$)$ & 0.87 & $0 \ddagger$ \\
\hline $\begin{array}{l}\text { Spending some time }(>0 \%) \\
\text { withdrawn }\end{array}$ & $71 / 153(46)$ & $56 / 149(38)$ & $8.8(-25.2$ to 42.8$)$ & 0.58 & 0.22 \\
\hline
\end{tabular}

Adjusted for clustering (estimated from weighted $t$ test).

†Mean of medians (data skewed, therefore median appropriate as summary statistic for each cluster).

†Truncated at zero.

§Range 29-203; higher scores mean more agitation (scores $>40$ usually accepted as clinically significant).

§Range 29-203;
IRange -5 to 5 .

**Estimated using dementia care mapping. 


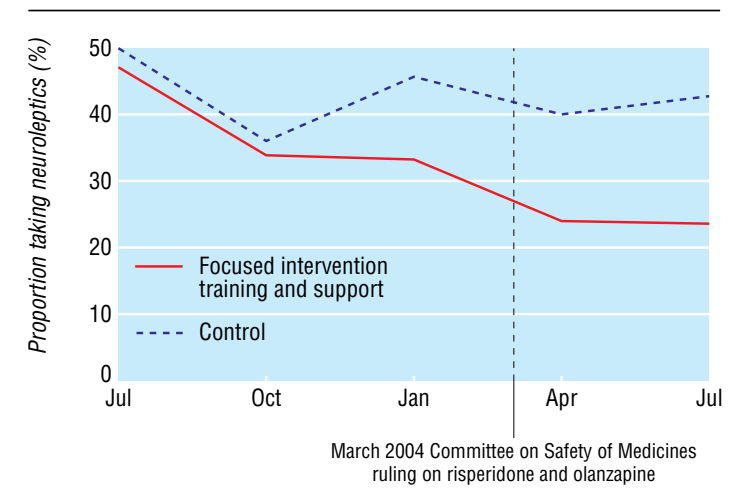

Fig 4 Neuroleptic use over study period, July 2003 to June 2004

improvement in behaviour and a trend towards a reduction in neuroleptic use.

Failure of the training and support intervention to have a significant effect on any of the secondary outcome measures may reflect difficulties inherent in affecting the culture of care within a nursing home enabling change to be measured in such a small scale trial.

In March 2004 the Committee on Safety of Medicines wrote to all doctors in the United Kingdom to advise against the prescription of risperidone and olanzapine in patients with dementia. The effect of this communication, which might have been expected to result in discontinuation of neuroleptics in a large number of participants in both arms of the trial, was only modest. Differences in the proportion of patients receiving neuroleptics at each review (fig 4 ) between the groups were sustained over the year, and similarly affected by the ruling of the Committee on Safety of Medicines.

The nursing homes that agreed to participate reflected a typical range of care provision for people with dementia in the United Kingdom and included three private individually owned and managed facilities, seven homes belonging to different large groups of care home providers, and two NHS managed facilities. Despite such heterogeneity between ownership and management of the homes and the geographical spread of the study, the training and support intervention was accompanied by significant reductions in the numbers of residents prescribed neuroleptics across the country.

\section{What is already known on this topic}

A high proportion of nursing home residents with dementia are treated with neuroleptics

The long term efficacy of neuroleptics in the management of behavioural disturbance in dementia has not been proved and their use is associated with increased morbidity and mortality

Withdrawal of neuroleptics does not acutely worsen behavioural symptoms of dementia

\section{What this study adds}

The training and support of care home staff reduced neuroleptic use in residents with dementia in nursing homes without worsening behavioural symptoms

The reduction in neuroleptic use was sustained for 12 months
We thank the residents and their family carers and staff of the homes. Rosamund Weatherall provided statistical support. Barbara Carlton, Brenda Barber, and Cathryn Roblett acted as consumer monitors for the Alzheimer's Society. Katrina Gasson, Karen Hathaway, and Jill Sawyer were the research clinicians. Jessica Baker, Sarah Barrett, Roland Burke, Ruth Elvish, and Sarah Wilmarsh collected data.

Contributors: RH, RJ, and CB conceived the study and obtained funding. All authors contributed to the study design, carrying out the study, and preparing the manuscript. EJ and NA contributed to the statistical analysis. RH is the guarantor.

Funding: Grant from the Alzheimer's Society, funded by the Community Fund.

Competing interests: $\mathrm{CB}$ is director of research for the Alzheimer's Society and has received payment for attending advisory boards from Janssen, AstraZeneca, and Bristol-Myers Squibb. RH has spoken at educational events sponsored by Janssen and has acted as a paid consultant for BristolMyers Squibb.

Ethical approval: Northern and Yorkshire regional multicentre research ethics committee and local committees in Oxford, Newcastle, and London.

1 McGrath AM, Jackson GA. Survey of prescribing in residents of nursing homes in Glasgow. BMJ 1996;314: 611-2

2 Margallo-Lana M, Swann A, O'Brien J, Fairbairn A, Reichelt K, Potkins D, et al. Prevalence and pharmacological management of behavioural and psychological symptoms amongst dementia sufferers living in care environments. Int J Geriatr Psychiatr 2001;16:39-44.

3 DeDeyn PP, Rabheru K, Rasmussen A, Bocksberger JP, Dautzenberg PL, Eriksson S, et al. A randomised trial of risperidone, placebo and haloperidol for behavioural symptoms of dementia. Neurol 1999;53:946-55.

4 Street JS, Clark WS, Gannon KS, Cummings JL, Bymaster FP, Tamura RN, et al. Olanzapine treatment of psychotic and behavioural symptoms in patients with Alzheimer's disease in nursing care facilities: a double-blind randomised, placebo-controlled trial. Arch Gen Psychiatr 2000;57:968-76.

5 Sink KM, Holden KF, Yaffe K. Pharmacological treatment of neuropsychiatric symptoms of dementia: a review of the evidence. JAMA 2005;293:596-608.

6 Howard R, Ballard C, O'Brien J, Burns A. Guidelines for the management of agitation in dementia. Int J Ger Psychiatr 2001;16:714-7.

7 Ballard C, O'Brien J, James I, Mynt P, Lana M, Potkins D, et al. Quality of life for people with dementia living in residential and nursing home care: the impact of dependency, behaviour and psychotropic drugs. Int Psychogeriatr 2001;13:93-106.

8 Cohen-Mansfield J, Werner P. Management of verbally disruptive behaviors in nursing home residents. J Gerontol A Biol Sci Med Sci 1997;52:M369-77.

9 Rovner BW, Steele C, Shmuely DS, Folstein MF. A randomised trial of dementia care in nursing homes. J Am Geriatr Soc 1996;44:7-13.

10 Brooker D, Foster N, Banner A, Payne M, Jackson L. The efficacy of dementia care mapping as an audit tool: a report of a 3 year British NHS evaluation. Ageing Ment alth $1998 \cdot 2 \cdot 60-70$

11 Aylward S, Stolee P, Keat N, Johncox V. Effectiveness of continuing education in long term care: a literature review. Gerontologist 2003;43:259-71.

12 Donner A. Some aspects of the design and analysis of cluster randomisation trials. Appl Statist 1998;47:95-113.

13 Cohn MD, Smyer MA. Mental health consultation: process, professions and models. In: Smyer MA, Cohn M, Brannon D, eds. Mental health consultation in nursing homes. New York: New York University Press, 1990.

14 Kitwood T. Dementia reconsidered. Buckingham: Open University Press, 1997.

15 Edberg AK, Norberg A, Hallberg IR. Mood and general behaviour of patients with severe dementia during one year of supervised, individualized planned care and systematic clinical supervision. Comparison with a similar control group. Aging 1999;11:395-403.

16 Stevens AB, Burgio LD, Bailey E, Burgio K, Paul P, Capilouto E, et al. Teaching and maintaining behaviour management skills with nursing assistants in a nursing home. Gerontologist 1998;38:379-84

17 Lai CKY, Chi I. A randomized controlled trial of a specific reminiscence approach to promote the well being of nursing home residents with dementia. Int Psychogeriatr 2004;16:33-49.

18 James I, Powell I, Kendell K. The castle and the know-it-all-access to the inner circle. J Dementia Care 2003;11:24-6.

19 Cole RP, Scott S, Skelton-Robinson M. The effect of challenging behaviour and staff support on the psychological wellbeing of staff working with older adults. Aging Ment Health 2000;4:359-65.

20 Cohen-Mansfield J. Agitated behaviors in the elderly. II. Preliminary results in the cognitively deteriorated. JAm Geriatr Soc 1986;34:722-7.

21 Kitwood T, Bredin K. Evaluating dementia care the DCM method. 7th ed. Bradford: Bradford Dementia Research Group, Bradford University, 1997.

22 Donner A, Klar N. Design and analysis of cluster randomised trials in health research. London: Arnold, 2000

23 Yudkin PL, Moher M. Putting theory into practice: a cluster randomised trial with a small number of clusters. Stat Med 2001;20:341-9.

(Accepted 23 February 2006)

doi $10.1136 /$ bmj.38782.575868.7C

Oxford University and Oxford Mental Healthcare Trust, Oxford Jane Fossey consultant clinical psychologist

King's College London, Institute of Psychiatry, MRC Centre for Neurodegeneration Research, London SE5 8AF 


\section{Research}

Clive Ballard professor of age related illnesses

Robert Howard professor of old age psychiatry

Centre for Statistics in Medicine, Wolfson College, University of Oxford Edmund Juszczak senior medical statistician

Nicola Alder medical statistician

Centre for the Health of the Elderly, University of Newcastle upon Tyne Ian James consultant clinical psychologist,

Department of Psychiatry, University of Oxford

Robin Jacoby professor of old age psychiatry

Correspondence to: Robert Howard r.howard@iop.kcl.ac.uk

\section{Amendment}

This is Version 2 of the paper. In this version, figure 2 has been amended to include all nursing homes [one was missing from the previous version]. 